Article

\title{
Dual-Modal In Vivo Fluorescence/Photoacoustic Microscopy Imaging of Inflammation Induced by GFP-Expressing Bacteria
}

\author{
Yubin Liu, Lei Fu, Mengze Xu, Jun Zheng and Zhen Yuan *(1) \\ Cancer Center, Faculty of Health Sciences, University of Macau, Macau SAR 999078, China; \\ yubinliu@umac.mo (Y.L.); leifu@umac.mo (L.F.); mengzexu@umac.mo (M.X.); junzheng@umac.mo (J.Z.) \\ * Correspondence: zhenyuan@umac.mo
}

Received: 20 November 2018; Accepted: 10 December 2018; Published: 10 January 2019

\begin{abstract}
In this study, dual-modal fluorescence and photoacoustic microscopy was performed for noninvasive and functional in vivo imaging of inflammation induced by green fluorescent protein (GFP) transfected bacteria in mice ear. Our imaging results demonstrated that the multimodal imaging technique is able to monitor the tissue immunovascular responses to infections with molecular specificity. Our study also indicated that the combination of photoacoustic and fluorescence microscopy imaging can simultaneously track the biochemical changes including the bacterial distribution and morphological change of blood vessels in the biological tissues with high resolution and enhanced sensitivity. Consequently, the developed method paves a new avenue for improving the understanding of the pathology mechanism of inflammation.
\end{abstract}

Keywords: GFP-expressing bacteria; biosensor; inflammation/infection; fluorescence imaging; photoacoustic microscopy

\section{Introduction}

Inflammation denotes the immunovascular responses of biological tissues to harmful stimuli such as the pathogens, damaged cells, or irritants, which generally involves the immune cells, blood vessels, and molecular mediators [1]. Imaging of inflammation in vivo can pave a new avenue for improved understanding of the pathophysiology associated with various disease etiologies, such as heart disease, cancer, chronic respiratory disease, stroke, Alzheimer's, diabetes, pneumonia, kidney disease, and flu [2-11]. Importantly, a number of non-invasive imaging techniques such as MRI, ultrasound, and CT, have been provided to study the biological mechanism of inflammation [12]. Among all imaging methods available, photoacoustic imaging (PAI) has exhibited its unique advantages in capturing both anatomy and function information of biological tissues with high optical contrast and high acoustic resolution [13-20]. PAI is a hybrid imaging technique that uses a pulsed laser to generate an acoustic wave. As the acoustic scattering is much lower than that from photonics, we can generate a high-resolution photoacoustic image.

Present PAI has two major implementations: focused-scanning photoacoustic microscopy (PAM) and photoacoustic computed tomography (PACT). PAM aims to image millimeters deep at micrometer scale resolution, whereas PACT can be carried out to image centimeters deep at half-millimeter scale resolution. Typically, PAM enables the microcirculation/disease microenvironment studies of small animal models, revealing disease-induced abnormal microcirculations/vascular changes of biological tissues in vivo. [21-23]. By contrast, fluorescence imaging (FLI) is a very unique molecular imaging method, which has been extensively adopted as a powerful tool for inspecting cellular level events and cancer theranostics [24-26]. 
In this study, dual-modal fluorescence microscopy and photoacoustic microscopy imaging was presented as a high-sensitivity modality for inflammation detection and monitoring, which is able to take advantages of the complementary information from each technique. Single clones of GFP-expressing enteropathogenic E. coli were cultured in LB medium at $37{ }^{\circ} \mathrm{C}$ overnight. In addition, PAM and fluorescence microscopy imaging were performed based on the developed animal inflammation model after the injection of GFP-transfected bacteria. Consequently, fluorescence microscopy imaging can effectively map the diseased tissue with inflammation and track the distribution of bacteria in the biological tissues, whereas PAM can identify the in vivo immunovascular response including the vascular structure changes to inflammation. Since it is hard to distinguish and confirm the differences between the normal and inflamed tissue with one imaging modality, the developed dual-modal fluorescence and photoacoustic microscopy imaging approach definitely exhibits its unbeatable advantages in inspecting the inflammatory pathogenesis for various preclinical applications and clinical practices [27].

\section{Methods and Materials}

\subsection{Preparation of GFP-transfected E. coli and In Vivo Animal Model}

The GFP-transfected E. coli was cultured in a liquid Luria-Bertani (LB) medium ( $3 \mathrm{~mL}$ ) at $37^{\circ} \mathrm{C}$ overnight. The fluorescence intensity of GFP-transfected bacteria (or bacteria viability) after overnight cultured was quantified by microplate reader with excitation wavelength of $488 \mathrm{~nm}$ and emission wavelength at $525 \mathrm{~nm}$. Next, the liquid LB medium was put on the orbital shaker incubator for $10-12 \mathrm{~h}$, in which the shaking speed and temperature was set as $200 \mathrm{rpm}$ and $37^{\circ} \mathrm{C}$, respectively. Further, the bacteria was washed with phosphate-buffered saline (PBS; Gibco, Thermo Fisher Scientific, Waltham, MA, USA) once and suspended in PBS. Finally, the bacteria was triply washed with PBS and then suspended in PBS to various concentrations for later imaging studies.

In addition, six eight-week old nude mice were used in this study. In vivo experiments were performed in compliance with the guidelines on animal research stipulated by the Animal Care and Use Committee at the University of Macau. After the mice were anesthetized with anesthesia machine (Isoflurane, R580, RWD Life Science, San Diego, CA, USA), the mice ear was imaged with our dual-modal photoacoustic and fluorescence microscopy systems before the bacteria infection. Furthermore, a $1 \mathrm{~mL}$ syringe with $30 \mathrm{~g}$ needle was utilized to inject the bacteria (concentration of $10^{8} \mathrm{cFU} / \mathrm{mL}, 50 \mu \mathrm{L}$ ) into the mice ear site to induce infection and later inflammation. Hereafter, the mice ear was imaged at $6 \mathrm{~h}$ post-injection by using the dual-modal imaging system.

\subsection{The Dual-Modal Photoacoustic and Fluorescence Microscopy Imaging Systems}

The homemade optical-resolution photoacoustic microscopy imaging system is provided in Figure 1, in which the pulsed laser (wavelength: $532 \mathrm{~nm}$; pulse width: $1 \mathrm{~ns}$; and repetition rate: up to $5 \mathrm{KHz}$ ) was used to illuminate the animals. The light beam first went through an optical subsystem (NDF: neutral density filter; CL1 and CL2: convex lens; PH: pinhole; OF: optical fiber), which was subsequently coupled with a single-mode fiber. Next, the laser beam delivered by the fiber changed its transportation direction by a rectangular prism (RP) after passing through an objective lens (OL1). To generate a high-resolution photoacoustic image, the second objective lens (OL2) was utilized, by which the laser beam focused on the imaging areas. A two-dimensional motor (M1 and M2) stage was rotated to scan the mice ear. The mice ear was fixed upon the agar gel phantom, the ultrasonic transducer was placed under the phantom, and a thin layer of ultrasound gel was spread over the interface between the agar phantom and transducer. The photoacoustic signals detected using a $50 \mathrm{MHz}$ transducer with an element diameter of $5.08 \mathrm{~mm}$ and a focal length of $127 \mathrm{~mm}$ (VF 412, Valpey Fisher, Valpey Fisher, Hopkinton, MA, USA) were amplified by the amplifier (5073R, OLYMPUS, OLYMPUS CORPORATION, Waltham, MA, USA) and then collected on the computer to generate optical-resolution PAM images. 


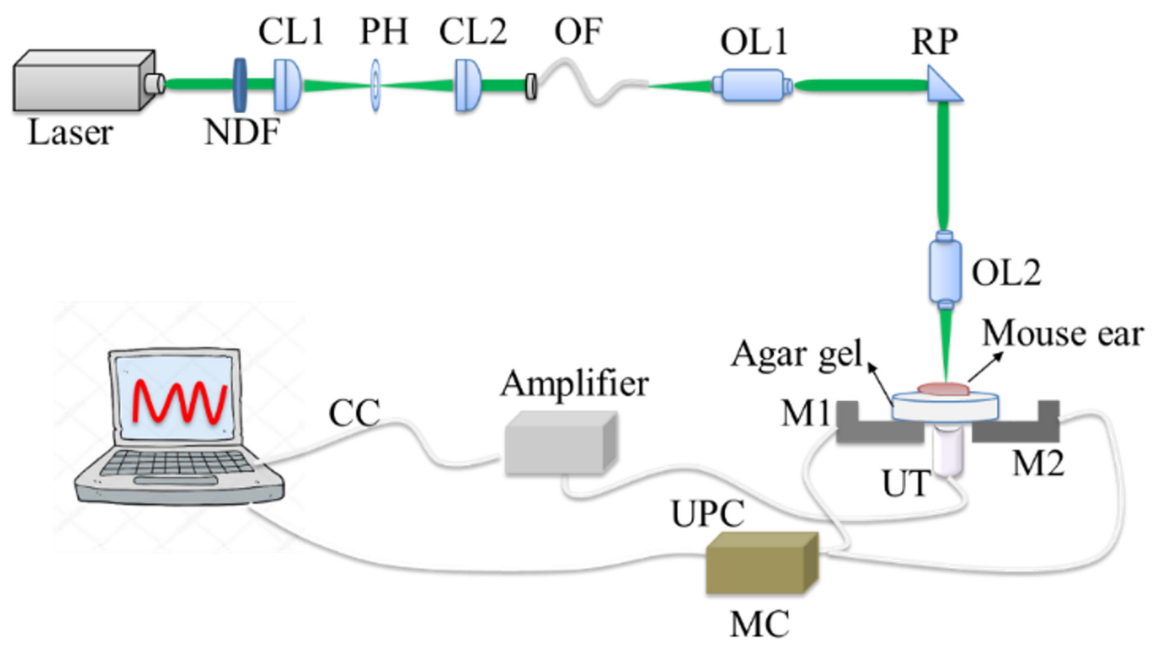

Figure 1. The home-made optical-resolution photoacoustic microscopy (PAM) imaging system. NDF: Neutral density filter; PH: pinhole; CL1 and CL2: Convex lens; OF: Optical fiber; OL1 and OL2: Objective lens; RP: Rectangular prism; M1 and M2: Two-dimensional motor; MC: Motor Control; UT: Ultrasonic transducer; UPC: Ultrasonic probe cable; and CC: Coaxial cable.

Specifically, the FLI system (eclipse Ni-U, Nikon Inc.) is a microscopy setup. As shown in Figure 2, this system consists of the mercury lamp, achromatic condenser, and CCD camera. For the present imaging system, the excitation wavelength is $488 \mathrm{~nm}$ and the emission filters used is $525 \sim 550 \mathrm{~nm}$. In addition, the integration time (exposure time) is $100 \mathrm{~ms}$, the objective magnification is $10 \mathrm{x}$, and the numerical aperture (N.A) is 0.3 .

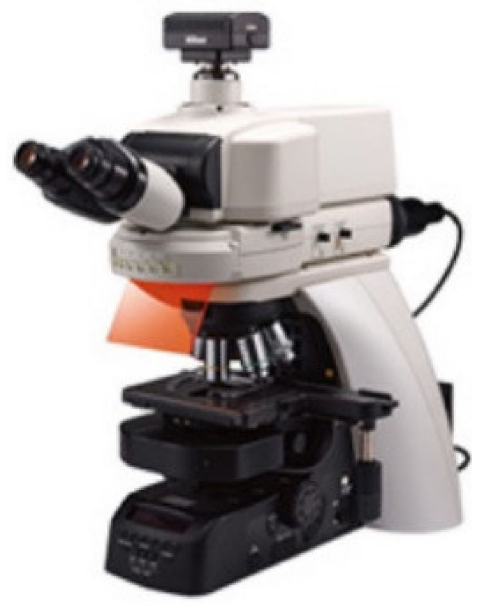

Figure 2. The commercial fluorescence microscopy imaging system.

\section{Results and Discussion}

\subsection{Relationship between the Various Concentrations of GFP-Expressing Bacteria and Fluorescence Signals}

The fluorescence imaging capability of GFP-expressing bacteria with various concentration was examined; the results are provided in Figure 3. The fluorescence images regarding the medium filled with GFP-expressing bacteria with eight different individual concentrations $(0 \mathrm{cFU} / \mathrm{mL}$, $0.31 \times 10^{8} \mathrm{cFU} / \mathrm{mL}, 0.62 \times 10^{8} \mathrm{cFU} / \mathrm{mL}, 1.25 \times 10^{8} \mathrm{cFU} / \mathrm{mL}, 2.5 \times 10^{8} \mathrm{cFU} / \mathrm{mL}, 5 \times 10^{8} \mathrm{cFU} / \mathrm{mL}$, $10 \times 10^{8} \mathrm{cFU} / \mathrm{mL}$, and $20 \times 10^{8} \mathrm{cFU} / \mathrm{mL}$ ) was provided in Figure 3a. We discovered from Figure 3a,b that the fluorescence signals increased with increased concentrations of GFP-transfected E. coli. In contrast, as the GFP-expressing bacteria has the low optical absorption, the corresponding phantom 
tests were not performed based on PAM imaging, although PAM can capture the structure and function of high-absorption tissues, such as blood vessels.

(a)

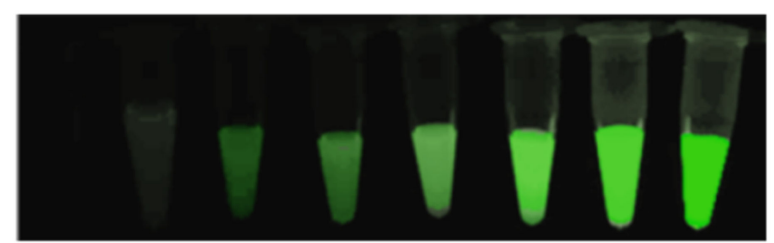

(b)

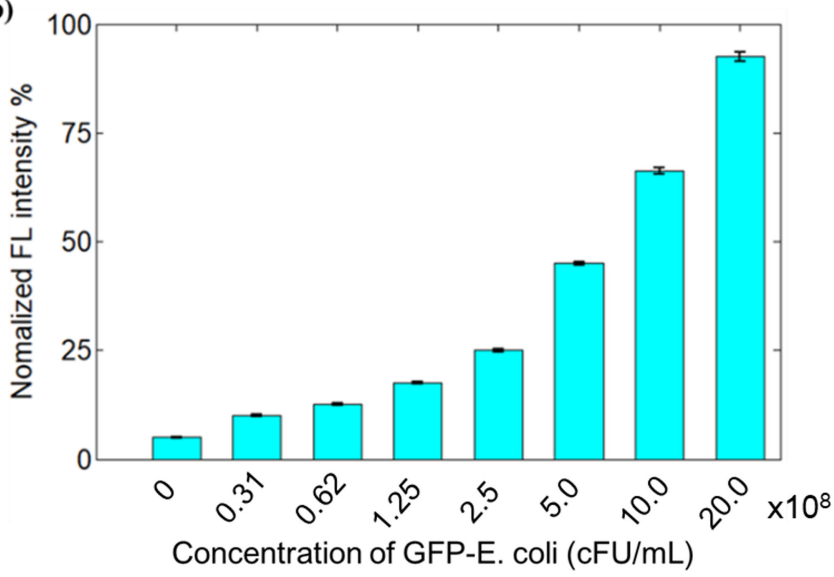

Figure 3. Fluorescence signals compared to different concentrations of green fluorescent protein (GFP)-transfected E. coli (a) and the relationship between the fluorescence intensity and various concentrations of GFP-transfected E. coli (b). cFU: Colony-Forming Units.

\subsection{Dual-Modal Imaging of Inflammation in Mice Ear}

To inspect the GFP-expressing bacteria in vivo, the dual modal PAM and fluorescence microscopy was carried out by using the mice ear model for the investigation of inflammatory pathogenesis. The mice ear was injected with GFP-expressing bacteria and fluorescence and photoacoustic images were collected at pre- and $6 \mathrm{~h}$ post-infection. In particular, Figure 4a displays the picture of a normal mice ear, whereas Figure $4 \mathrm{~b}$,c shows the generated PAM and fluorescence microscopy images before the bacteria injection. Likewise, Figure $4 \mathrm{~d}-\mathrm{f}$ shows the mice ear with inflammation, the reconstructed PAM and fluorescence images at $6 \mathrm{~h}$ post-infection, respectively. In addition, the inflammation was monitored for 5 days based on the dual-modal imaging method and the imaging results are provided in Figure 5 for another mouse.

\subsection{Discussion}

We discovered from Figure 4 that the fluorescence signals at $6 \mathrm{~h}$ post-injection was significantly enhanced in the inflammation area, which exhibited dramatically increased bacterial populations in the infection region. The imaging results also demonstrated that fluorescence microscopy can effectively map the diseased tissue with inflammation and track the distribution of bacteria in the biological tissues.

Interestingly, we also discovered from Figure 5 that no significantly increased fluorescence signal was detected before the injection. However, enhanced fluorescence signal was observed and kept nearly unchanged at day one post-injection. More importantly, from the third day, the fluorescence signal intensity began to decrease; five days later, the signals totally disappeared. The dual-modal imaging results indicated that the developed system can be used to diagnosis and monitor bacteria-induced inflammation. However, it cannot capture the micro-environment/vascular changes of mice ear with inflammation due to the interaction between the tissues and bacteria. In addition, fluorescence imaging cannot identify the structure and function of normal tissues without infection. 
By contrast, PAM can image the vascular structures of the normal mice ear. More importantly, as demonstrated in Figure 4e, inflammation with GFP-expressing bacteria in vivo can trigger strong immune response, which further result in increased blood vessels surrounding the infection site at $6 \mathrm{~h}$ post-infection (the oval represents the inflamed area). The results in Figure 5 also demonstrated that PAM imaging can effectively identify and monitor the vascular structures and micro-environment changes due to the inflammation.

(a)

(d)
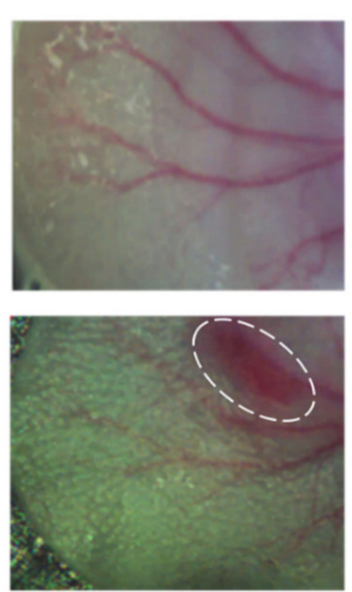

(b)

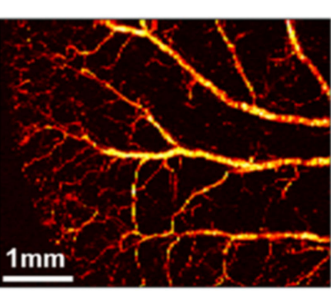

(e)

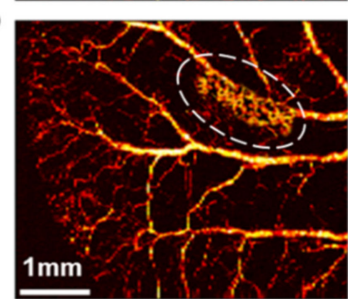

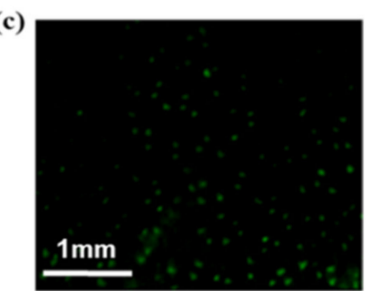

(f)

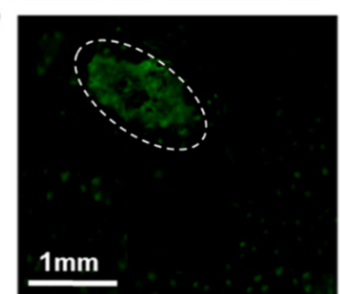

(g)

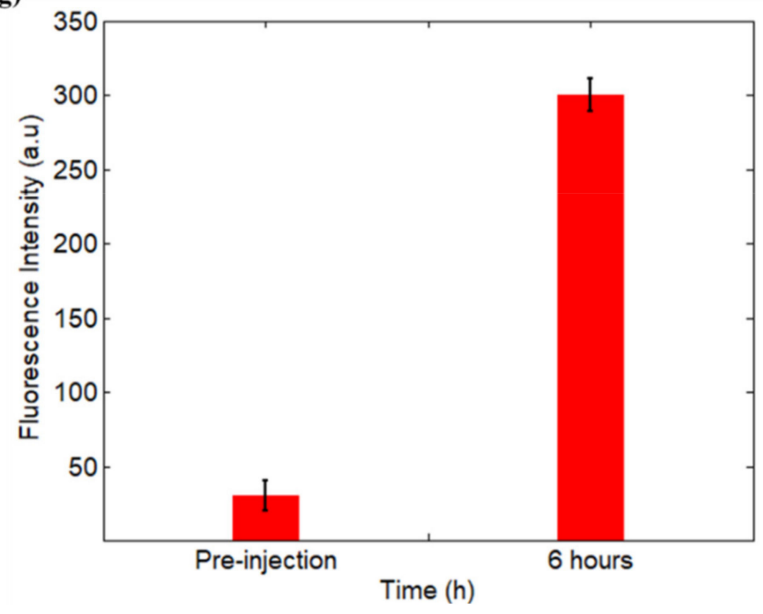

Figure 4. Dual-modal PAM and fluorescence microscopy imaging results for the first mouse. (a) The photography of normal mice ear; (b) PAM imaging of normal mice ear; (c) fluorescence microscopy imaging of normal mice ear; (d) photography of the same mice ear at $6 \mathrm{~h}$ post-injection; (e) PAM imaging of immunovascular response of mice ear with inflammation at $6 \mathrm{~h}$ post-injection; (f) fluorescence microscopy imaging of the bacteria distribution and inflammation regions of mice ear at $6 \mathrm{~h}$ post-injection; and (g) the corresponding fluorescence intensity at pre-injection and $6 \mathrm{~h}$ post-injection. 
(a)

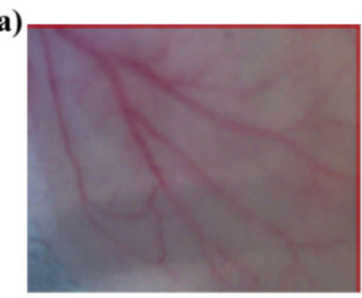

(d)

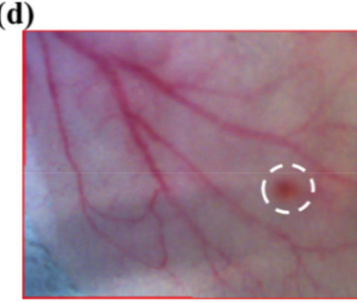

(g)

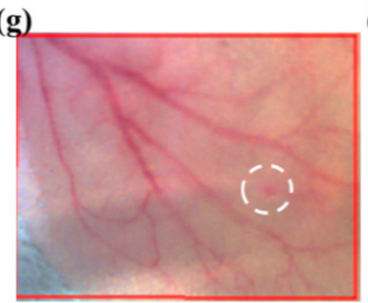

(j)

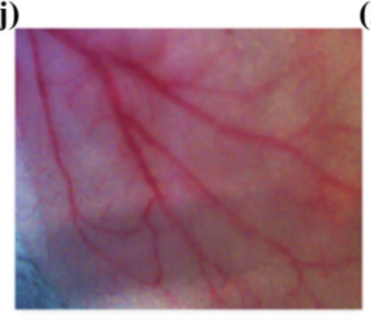

(e)

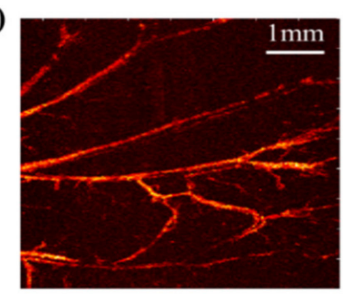

(e)
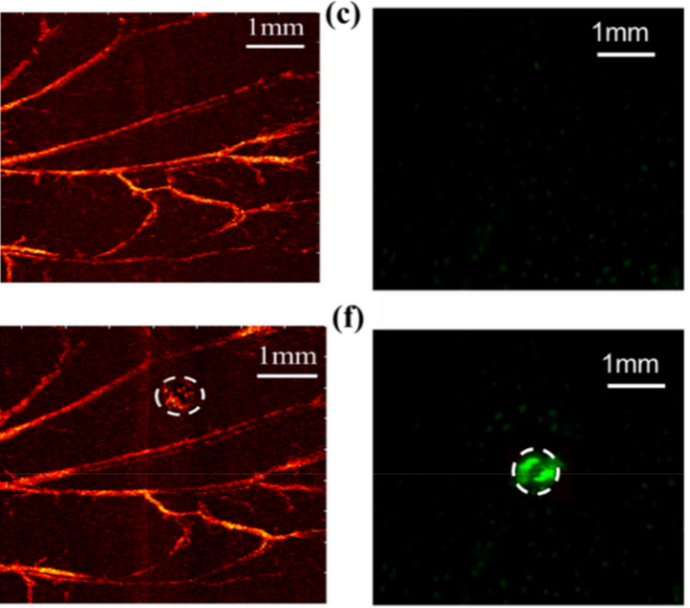

(f)

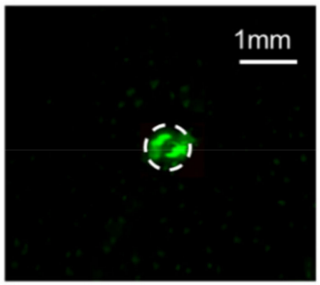

(h)

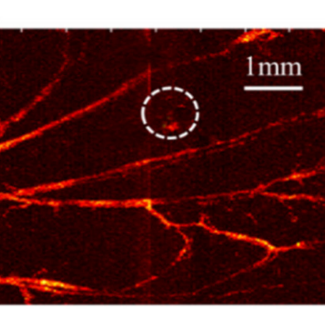

k)

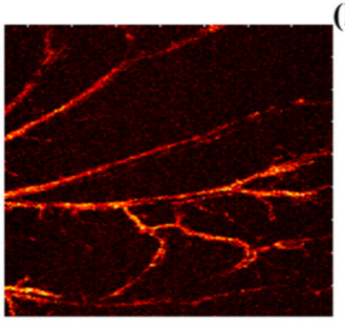

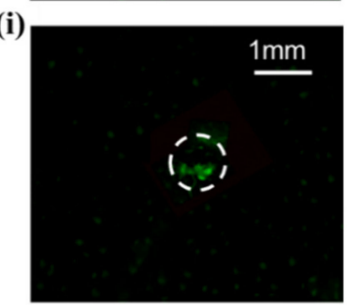

$1 \mathrm{~mm}$

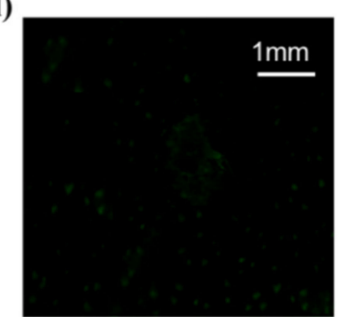

(m)

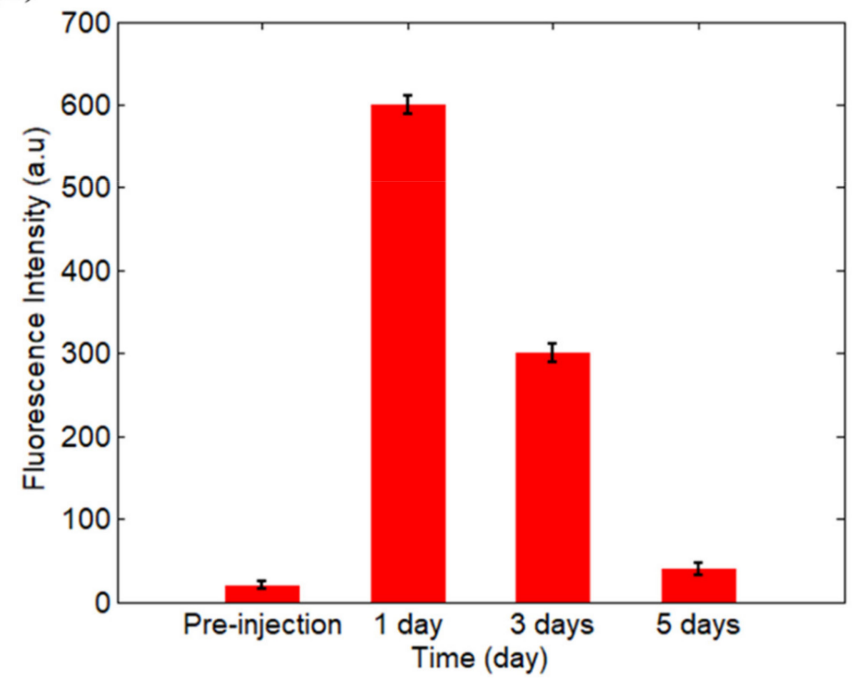

Figure 5. Dual-modal PAM and fluorescence microscopy imaging for monitoring the inflammation: $(\mathbf{a}-\mathbf{c})$ are the imaging results before the injection of bacteria; $(\mathbf{d}-\mathbf{f})$ are the results at 1 day post-injection; $(\mathbf{g}-\mathbf{i})$ are the results at 3 days post-injection; $(\mathbf{j}-\mathbf{l})$ are the results at 5 days post-injection. The first column showed the picture of mice ear, the second one displayed the photoacosutic image, whereas the third one exhibited the fluorescence image; $(\mathbf{m})$ the corresponding fluorescence intensity at pre-injection, 1 day, 3 days, and 5 days post-injection, respectively. 


\section{Conclusions}

In this study, homemade optical-resolution PAM systems combined with commercial fluorescence microscopy systems were used for imaging inflammation in mice ears. We discovered that mice ears with infections are a powerful animal model to study inflammatory pathogenesis. To date, it is still difficult to distinctively confirm the differences between normal and inflamed tissues by only using one imaging modality. As a result, dual-model imaging can be performed using PAM and fluorescence microscopy to improve the sensitivity for the detection and monitoring of inflammation.

Author Contributions: Z.Y. designed the experiments, Y.L., M.X., L.F., J.Z. and Z.Y. performed the experiments, and Y.L. and Z.Y. wrote the manuscript.

Funding: This study was supported by MYRG2016-00110-FHS and MYRG 2018-00081-FHS grants from the University of Macau in Macau, and FDCT 0011/2018/A1 and FDCT 025/2015/A1 grants from Macao government.

Conflicts of Interest: The authors declare no conflict of interest.

\section{References}

1. Ferrero-Miliani, L.; Nielsen, O.H.; Andersen, P.S.; Girardin, S.E. Chronic inflammation: Importance of NOD2 and NALP3 in interleukin-1 $\beta$ generation. Clin. Exp. Immunol. 2007, 147, 227-235. [CrossRef] [PubMed]

2. Mantovani, A. Cancer: Inflammation by remote control. Nature 2005, 435, 752. [CrossRef] [PubMed]

3. Yu, H.; Pardoll, D.; Jove, R. STATs in cancer inflammation and immunity: A leading role for STAT3. Nat. Rev. Cancer 2009, 9, 798. [CrossRef] [PubMed]

4. Seemungal, T.; Harper-Owen, R.; Bhowmik, A.; Moric, I.; Sanderson, G.; Message, S.; MacCALLUM, P.E.; Meade, T.W.; Jeffries, D.J.; Johnston, S.L.; et al. Respiratory viruses, symptoms, and inflammatory markers in acute exacerbations and stable chronic obstructive pulmonary disease. Am. J. Respir. Crit. Care Med. 2001, 164, 1618-1623. [CrossRef] [PubMed]

5. Sevenoaks, M.J.; Stockley, R.A. Chronic Obstructive Pulmonary Disease, inflammation and co-morbidity-A common inflammatory phenotype? Respir. Res. 2006, 7, 70. [CrossRef] [PubMed]

6. Huang, J.; Upadhyay, U.M.; Tamargo, R.J. Inflammation in stroke and focal cerebral ischemia. Surg. Neurol. 2006, 66, 232-245. [CrossRef] [PubMed]

7. Emsley, H.C.A.; Tyrrell, P.J. Inflammation and infection in clinical stroke. J. Cereb. Blood Flow Metab. 2002, 22, 1399-1419. [CrossRef]

8. Akiyama, H.; Barger, S.; Barnum, S.; Bradt, B.; Bauer, J.; Cole, G.M.; Cooper, N.R.; Eikelenboom, P.; Emmerling, M.; Fiebich, B.L.; et al. Inflammation and Alzheimer's disease. Neurobiol. Aging 2000, 21, 383-421. [CrossRef]

9. Navarro, J.F.; Mora, C. Diabetes, inflammation, proinflammatory cytokines, and diabetic nephropathy. Sci. World J. 2006, 6, 908-917. [CrossRef]

10. Peper, R.L.; Van Campen, H. Tumor necrosis factor as a mediator of inflammation in influenza A viral pneumonia. Microb. Pathog. 1995, 19, 175-183. [CrossRef]

11. Rainsford, K.D. Influenza ("Bird Flu"), inflammation and anti-inflammatory/analgesic drugs. Inflammopharmacology 2006, 14, 2-9. [CrossRef] [PubMed]

12. Hammoud, D.A. Molecular imaging of inflammation: Current status. Journal of nuclear medicine: Official publication. Soc. Nuclear Med. 2016, 57, 1161. [CrossRef] [PubMed]

13. Zhang, E.Z.; Laufer, J.G.; Pedley, R.B.; Beard, P.C. In vivo high-resolution 3D photoacoustic imaging of superficial vascular anatomy. Phys. Med. Biol. 2009, 54, 1035. [CrossRef] [PubMed]

14. Agarwal, A.; Huang, S.W.; O'donnell, M.; Day, K.C.; Day, M.; Kotov, N.; Ashkenazi, S. Targeted gold nanorod contrast agent for prostate cancer detection by photoacoustic imaging. J. Appl. Phys. 2007, 102, 064701. [CrossRef]

15. Yuan, Z.; Li, X.; Xi, L. Listening to light scattering in turbid media: Quantitative optical scattering imaging using photoacoustic measurements with one-wavelength illumination. J. Opt. 2014, 16, 065301. [CrossRef]

16. Liu, Y.; Jiang, H.; Yuan, Z. Two schemes for quantitative photoacoustic tomography based on Monte Carlo simulation. Med. Phys. 2016, 43, 3987-3997. [CrossRef] [PubMed]

17. Liu, Y.; Yuan, Z. Multi-spectral photoacoustic elasticity tomography. Biomed. Opt. Express 2016, 7, 3323-3334. [CrossRef] 
18. Gao, D.; Sheng, Z.; Liu, Y.; Hu, D.; Zhang, J.; Zhang, X.; Zheng, H.; Yuan, Z. Protein-Modified CuS Nanotriangles: A Potential Multimodal Nanoplatform for In Vivo Tumor Photoacoustic/Magnetic Resonance Dual-Modal Imaging. Adv. Heal. Mater. 2017, 6, 1601094. [CrossRef]

19. Zhang, J.; Chen, H.; Zhou, T.; Wang, L.; Gao, D.; Zhang, X.; Liu, Y.; Wu, C.; Yuan, Z. A PIID-DTBT based semi-conducting polymer dots with broad and strong optical absorption in the visible-light region: Highly effective contrast agents for multiscale and multi-spectral photoacoustic imaging. Nano Res. 2017, 10, 64-76. [CrossRef]

20. Wang, X.; Xie, X.; Ku, G.; Wang, L.V.; Stoica, G. Noninvasive imaging of hemoglobin concentration and oxygenation in the rat brain using high-resolution photoacoustic tomography. J. Biomed. Opt. 2006, 11, 024015. [CrossRef]

21. Yao, J.; Wang, L.; Yang, J.M.; Maslov, K.I.; Wong, T.T.; Li, L.; Huang, C.H.; Zou, J.; Wang, L.V. High-speed label-free functional photoacoustic microscopy of mouse brain in action. Nat. Methods 2015, 12, 407. [CrossRef] [PubMed]

22. Hu, S.; Rao, B.; Maslov, K.; Wang, L.V. Label-free photoacoustic ophthalmic angiography. Opt. Lett. 2010, 35 , 1-3. [CrossRef] [PubMed]

23. Gao, D.; Liu, Y.; Wang, Y.; Yuan, Z. Protein-modified ultra-small gold clusters for dual-modal in vivo fluorescence/photoacoustic imaging. Quant. Imaging Med. Surg. 2018, 8, 326. [CrossRef] [PubMed]

24. Ntziachristos, V.; Ripoll, J.; Wang, L.V.; Weissleder, R. Looking and listening to light: The evolution of whole-body photonic imaging. Nat. Biotechnol. 2005, 23, 313. [CrossRef] [PubMed]

25. Luker, G.D.; Luker, K.E. Optical imaging: Current applications and future directions. J. Nuclear Med. 2008, 49, 1. [CrossRef] [PubMed]

26. Ntziachristos, V.; Tung, C.H.; Bremer, C.; Weissleder, R. Fluorescence molecular tomography resolves protease activity in vivo. Nat. Med. 2002, 8, 757. [CrossRef] [PubMed]

27. Langer, G.; Buchegger, B.; Jacak, J.; Klar, T.A.; Berer, T. Frequency domain photoacoustic and fluorescence microscopy. Biomed. Opt. Express 2016, 7, 2692-2702. [CrossRef]

(C) 2019 by the authors. Licensee MDPI, Basel, Switzerland. This article is an open access article distributed under the terms and conditions of the Creative Commons Attribution (CC BY) license (http:/ / creativecommons.org/licenses/by/4.0/). 